\title{
Modern aspects on tri- and tetranuclear cluster complexes supported by phosphido bridges
}

\author{
H -J HAUPT \\ Universität-GH Paderborn, 33098 Paderborn, Germany \\ e-mail: haupt@chemie.uni-paderborn.de
}

\begin{abstract}
This report on small cluster complexes with metal-metal bonds in the field of coordination chemistry documents results in the following scientific areas. (1) Systematic synthetic routes via ditransition metal carbonyl derivative of manganese and rhenium (group 7) to functionalized triangulo- and tetrahedro-clusters including structural characterization, (2) Dynamic properties of mono- and diauration isomers like $\mathrm{M}_{2}\left(\mathrm{mAuPR}_{3}\right)(\mathrm{mPCyH})(\mathrm{CO})_{8} / \mathrm{M}_{2}(\mathrm{mH})\left(\mathrm{m}-\mathrm{PCy}\left(\mathrm{AuPR} \mathrm{P}_{3}\right)\right)(\mathrm{CO})_{8} \quad$ (isomerization) and $\mathrm{M}_{2}\left(\mathrm{mAuPR}_{3}\right)_{2}(\mathrm{~m}-\mathrm{PCy})(\mathrm{CO})_{8} / \mathrm{M}_{2}\left(\mathrm{mAuPR}_{3}\right)\left(\mathrm{m}-\mathrm{PCy}\left(\mathrm{AuPR}_{3}\right)\right)(\mathrm{CO})_{8}(\mathrm{M}=\mathrm{Mn}, \mathrm{Re}$; $\mathrm{R}=$ organic residue) (rearrangement and valence isomerization) and $\mathrm{MM} \phi(\mathrm{mH})(\mathrm{m}$ $\left.\mathrm{PCy}_{2}\right)\left(\mathrm{m}_{4}-\mathrm{PCy}\left(\mathrm{AuPR}_{3}\right)\right)(\mathrm{CO})_{6}(\mathrm{M}=\mathrm{M} \phi \mathrm{M} \pi \mathrm{M} \phi$ (topomerization) going from one to the other homologue and the kinetic study of isomerization in the framework $\mathrm{Re}_{2}\left(\mathrm{AuPCy}_{3}\right)_{2}\left(\mathrm{mPMeN}_{2}(\mathrm{mC}(\mathrm{Bu}) \mathrm{O})(\mathrm{CO})_{6}\right.$, (3) Correlations of chirality transfer in diastereomeric tetrahedro-clusters $\left.\operatorname{Re}_{2}\left(\mathrm{M}^{1} \mathrm{PR}_{3}\right)_{2}(\mathrm{mPCy})_{2}\right)(\mathrm{CO})_{7}\left(\mathrm{~h}^{1}-\mathrm{L}^{*}\right) \quad\left(\mathrm{M}^{1}=\right.$ coin metals, $\mathrm{L}^{*}=$ chiral ligand as $(+)$ or $(-)$ prolinate, for example) from $\mathrm{CD}$ data. These selected contributions will be discussed to answer the question "Do small cluster complexes remain as a future challenge in cluster chemistry?"
\end{abstract}

Keywords. Heterometallic cluster complexes; hydroformylation catalysts; topomerization process; diastereomers; isomerization process.

\section{Introduction}

Tri- and tetranuclear clusters belong to the family of small cluster complexes. The main features of this family are the presence of structurally deciding metal-metal interactions and metal aggregation numbers, usually within 3 to $10^{1,2}$. The small clusters deserve special interest to study the selectivity of formation in heterometallic examples, reaction patterns of multifunctionalized clusters, rigid and non-rigid behaviour of metal frameworks in ligand spheres, chirality transfer of rigid metal frameworks, development of homogeneous catalysts with cooperative effects, surface chemistry of heterogeneous catalysts used in industrial processes via mimics and finally perhaps the property of bulk materials which are modified by clusters in material science.

In a subsequent report ${ }^{3}$, some results of our studies on the title compounds related to the design of heterometallic clusters in systematic syntheses were presented. The consideration begins with the transition metals in group 7. The latter form a metal-metal bound fragment which is stabilized with a phosphido bridge as a common ligand in dinuclear complexes. This is done in order to maintain the metal-metal arrangement in the following reaction sequences. Such precursor complexes are selectively reacted to get functional intermediates which allow the stepwise formation of tri- and tetranuclear clusters as desired. The description of the results is enumerated in the following sections. 


\section{Results and discussion}

\subsection{Preparation}

A conceptual demand is generally the development of a selective reaction pattern to get the so-called main compound which allows the preparation of numerous derivatives in satisfactory yields. For example, methods to synthesize the twofold unsaturated trinuclear rhenium clusters such as $\mathrm{Re}_{3}(\mathrm{~m}-\mathrm{H})(\mathrm{mH})\left(p-\mathrm{XC}_{6} \mathrm{H}_{4}\right)_{2}(\mathrm{CO})_{6} \quad(\mathrm{X}=\mathrm{H}, \quad \mathrm{F})$ and similar tetranuclear rhenium clusters are unselective and rather time-consuming ${ }^{4}$. To surmount our problems with respect to low selectivity, we have designed the synthesis of the new concept heterometallic clusters. One conceptual part was the synthesis of triangular clusters with $\mathrm{M}_{2} \mathrm{Rh}$ core $\left(\mathrm{M}=d^{7}\right.$ metal) to test their feasibility as hydroformylation catalysts. The earlier and recent results obtained will be ascertained as follows.

In the beginning, our preparative efforts led to two types of clusters $\mathrm{M}^{1} \mathrm{M}^{2}(\mathrm{~m}$ $\left.\mathrm{PCy}_{2}\right)(\mathrm{CO})_{8} \mathrm{Rh}(\mathrm{CO})_{2} \mathrm{PPh}_{3}$ containing a [4 +2] coordination pattern at the $\mathrm{Re}(\mathrm{I})$ ring atom and $\mathrm{M}^{1} \mathrm{M}^{2}\left(\mathrm{mPCy}_{2}\right)(\mathrm{CO})_{8} \mathrm{RhPPh}_{3}\left(\mathrm{M}^{1}=\mathrm{M}^{2}=\mathrm{Mn}, \mathrm{Rh} ; \mathrm{M}^{1}=\mathrm{Mn}, \mathrm{M}^{2}=\mathrm{Re}\right)$ with the coordination number of three at the $\mathrm{Rh}(\mathrm{I})$. We found that only the compounds of the first type in a standard hydroformylation reaction $\left(p_{\mathrm{H}_{2}}=p_{\mathrm{CO}}=3\right.$ bar, $60^{\circ} \mathrm{C}$, substrate 1 hexene, solvent THF) were catalytically active ${ }^{5}$. Recently, we obtained such hydroformylation catalysts in high yields. Moreover the reaction behaviour of the leading compounds $\mathrm{M}_{2} \mathrm{Rh}\left(\mathrm{mPCy}_{2}\right)(\mathrm{mCO})_{2}(\mathrm{CO})_{8}(\mathrm{M}=\mathrm{Mn}, \mathrm{Re})$ was characterized by ligand substitution reaction, to determine the labile part of the ligand sphere. We have observed, in the reaction course with primary and secondary phosphines, that the terminal CO ligands attached at the $\operatorname{Re}(\mathrm{I})$ ring atom are more labile than the others. Going from the cluster of $\mathrm{Re}_{2} \mathrm{Rh}$ to that of the $\mathrm{Mn}_{2} \mathrm{Rh}$ core; it is only in the reaction of secondary phosphines $\mathrm{HPR}_{2}(\mathrm{R}=\mathrm{Cy}, \mathrm{Ph},(-)$ Menthyl), that a ring-opening of the $\mathrm{M}-\mathrm{M}$ bond in dimanganese rhodium cluster occurs with the formation of $\mathrm{MnRh}\left(\mathrm{mPCy}_{2}\right)(\mathrm{m}$ $\mathrm{H})(\mathrm{CO})_{5} \mathrm{Mn}\left(\mathrm{mPCy}_{2}\right)(\mathrm{CO})_{4}$. The last complex in solution shows a fluctuating heterometallic double bond ( $\mathrm{p}$ delocalisation effect) including a positional change of the $\mathrm{Rh}$ bound $\mathrm{CO}$ ligand and $\mathrm{mH}$ atom (on the time-scale of the NMR method used). Analogous ring-opening reaction could be realized with bidentate phosphines (bisdiphenylphosphinomethane, DPPM; 1,1-bis-diphenylphosphinoethene EPP) with the dirhenium and the dimanganese rhodium clusters $\mathrm{M}_{2} \mathrm{Rh}\left(\mathrm{mPCy}_{2}\right)(\mathrm{mCO})_{2}(\mathrm{CO})_{8}$. A chiral modification of the DPPM ligand is also possible. To establish the rate-determining step in the hydroformylation process the leading compounds as catalysts were reacted with hydrogen, $\mathrm{CO}_{(\mathrm{g})}$ and 1-hexene. The reaction course of such components will be described. From the experiments, it could be proposed that coordination of the olefin (substrate) is rate-determining. The reaction behaviour of the leading compounds as catalysts under hydroformylation conditions was next examined. The results suggest that the key compounds are ring-opened species as proved by ${ }^{1} \mathrm{H}$ and ${ }^{31} \mathrm{P}$ NMR measurements in a cuvette which is resistant to pressure.

The factors of influence in the hydroformylation reaction with this type of catalyst are presented in the section on homogeneous catalysts (see §3). Another topic of our preparative efforts was combined with the determination of the reactivity pattern of the complex type $\mathrm{M}_{2}(\mathrm{mH})(\mathrm{mPCyH})(\mathrm{CO})_{8}(\mathrm{M}=\mathrm{Mn}, \mathrm{Re})$ to ascertain selective monoauration and diauration products. The results obtained are described in our earlier papers ${ }^{6-8}$. To compare chemical properties of the homologue transition metals, the cluster $\mathrm{Mn}_{2}\left(\mathrm{AuPR}_{3}\right)_{2}(\mathrm{~m}-\mathrm{PCy})(\mathrm{CO})_{8}$ which shows a topomerization process which was triggered 
by the $\mathrm{m}$-P bridging atom was prepared. Our goal was to find the random conditions for the topomerization process using $\mathrm{Re}_{2} \mathrm{Au}_{2}$ core. The preparative study led to formation of new tetranuclear cluster complexes of the type $\mathrm{M}_{2}\left(\mathrm{AuPR}_{3}\right)_{2}(\mathrm{~m}-\mathrm{H})\left(\mathrm{mPCy}_{2}\right)(\mathrm{m}-\mathrm{PCy})(\mathrm{CO})_{6}$ $(\mathrm{M}=\mathrm{Mn}, \mathrm{Re} ; \mathrm{R}=\mathrm{Ph}, \mathrm{Cy}, \mathrm{Et})$ which show a topomerization process. The observed features allowed the following conclusions in this kind of tetranuclear clusters with alternating homo- and heteronuclear metal-metal bonds.

(1) This kind of isomerization via $\mathrm{M}$...Au edges in compounds with $\mathrm{M}_{2} \mathrm{Au}_{2}$ cores is generally facilitated by going from $\mathrm{Re}$ to $\mathrm{Mn}$ in cluster complexes with a $\mathrm{m}$ - $\mathrm{P}$ bridge as trigger.

(2) In order to form the corresponding compounds with $\mathrm{Re}_{2} \mathrm{Au}_{2}$ core, the homonuclear $\mathrm{Re}-\mathrm{Re}$ bond must be strengthened by introduction of at least two appropriate phosphorous bridges.

For the stabilization of compounds with $\mathrm{Mn}_{2} \mathrm{Au}_{2}$ core only one $\mathrm{m}$-P bridge is sufficient. Hence for the topomerization process the Re compounds always need a larger formal oxidation state than the corresponding Mn homologues and furthermore, partial contributions of metal and bridging orbitals in the formation of the HOMO is evident.

(3) A change from $\mathrm{Mn}_{2} \mathrm{Au}_{2}$ to $\mathrm{M}^{1} \mathrm{M}^{2} \mathrm{Au}_{2}$ core $\left(\mathrm{M}^{1} \neq \mathrm{M}^{2}\right)$ prevents the desired isomerization reaction ${ }^{9}$.

Finally, our preparative efforts are directed on synthetic routes to get rigid metallatetrahedron clusters. In an earlier paper, the stepwise synthesis of functionalized metallatetrahedron clusters $\mathrm{Re}_{2}\left(\mathrm{AuPPh}_{3}\right)_{2}\left(\mathrm{APCy}_{2}\right)(\mathrm{CO})_{7} \mathrm{X}(\mathrm{X}=\mathrm{Cl}, \mathrm{Br}, \mathrm{I})$ was illustrated. The chiral metallatetrahedron clusters could be obtained almost in quantitative yields, but our efforts to separate the enantiomers were unsuccessful. So we concentrated our studies on the synthesis of diastereomeric cluster anions as a precursor to obtain diastereomeric metallatetrahedron clusters. The latter examples could at least be separated by fractional crystallization procedures. To reach this aim, the first step comprised the synthesis of $h^{1}$-carboxylate substituted clusters of the type $\operatorname{Re}_{2}\left(\mathrm{AuPPh}_{3}\right)_{2}\left(\mathrm{mPCy}_{2}\right)(\mathrm{CO})_{7}$ $\left(h^{1}-\mathrm{OC}(\mathrm{R}) \mathrm{O}\right)\left(\mathrm{R}=\mathrm{H}, \mathrm{Me}, \mathrm{CF}_{3}, \mathrm{Ph}, 3,4(\mathrm{MeO})_{2} \mathrm{C}_{3} \mathrm{H}_{3}\right)$. Based on our knowledge of this preparative approach, the diastereomeric clusters $\operatorname{Re}_{2}\left(\mathrm{AuPPh}_{3}\right)_{2}\left(\mathrm{mPCy}_{2}\right)(\mathrm{CO})_{7}$ $\left(\mathrm{h}^{1}-\mathrm{L}^{*}\right)\left(\mathrm{L}^{*}-(-)\right.$ and $(+)$ prolinate) and $\mathrm{Re}_{2}\left(\mathrm{AuPPh}_{3}\right)\left(\mathrm{APCy}_{2}\right)(\mathrm{CO})_{7}\left(\mathrm{~h}^{1}-\mathrm{L}^{*}\right)\left(\mathrm{L}^{*}=(+)\right.$ and (-) camphanate) and others could be prepared. Also the separation of the diastereomers was successful. Finally, the separation of cluster type $\operatorname{Re}_{2}\left(\mathrm{AuPPh}_{3}\right)_{2}\left(\mathrm{mPCy}_{2}\right)(\mathrm{CO})_{6}(\mathrm{~mL}$ or $\left.\mathrm{L}^{*}\right)$ and $\mathrm{Re}_{2}\left(\mathrm{AuPPh}_{3}\right)_{2}\left(\mathrm{mPMen}_{2}\right)(\mathrm{mCBuO})(\mathrm{CO})_{6}$ including derivatives will be reported.

\subsection{Property}

Epimerization of $\operatorname{Re}_{2}\left(\mathrm{AuPCy}_{3}\right)_{2}\left(\mathrm{mPMen}_{2}\right)(\mathrm{mC}(\mathrm{n}-\mathrm{Bu}) \mathrm{O})(\mathrm{CO})_{6}(\mathrm{Men}=(-)$ menthyl). The earlier mentioned cluster derivative with tertiary $\mathrm{PPh}_{3}$ instead of $\mathrm{PCy}_{3}$ ligand attached at the gold(I) was formed with $d e$ value of $27 \%$. The usual chromatographic separation procedures did not give an enrichment of one diastereomer. Otherwise, one diastereomer (a non-conglomerate) crystallized from such diastereomeric mixtures. This fact was proved by a single-crystal analysis. But to our surprise, in the solution, the other diastereomer did not show the expected excess. This observation was ascertained by

${ }^{31} \mathrm{P}$ NMR data. To explain it, in spite of the presence of two bridging ligands, a permanent framework isomerization in the compound considered must be taken into account. To prove this idea, the title compound was chosen because the bigger Tolman cone angle of $170^{\circ}$ in $\mathrm{PCy}_{3}$ to that of $145^{\circ}$ in $\mathrm{PPh}_{3}$ would allow a higher activation barrier of the 
postulated isomerization process. At equilibrium the title compounds showed the ratio of $1 / 2.5(43 \% d e)$ in the diastereomeric mixture. A TLC separation procedure led to excess of one of the diastereomers. If such an enriched mixture of the diastereomers were dissolved, the concentration change to the equilibrium de value could be recorded by ${ }^{31} \mathrm{P}$ NMR and polarimetric measurements.

As expected, all data measured fulfil a framework isomerization process in a rate law of first order. The results at $298 \mathrm{~K}$ are given in table 1 .

The activation parameters are examined by means of ${ }^{31} \mathrm{P}$ NMR measurements at different temperatures. The data in table 2 are derived ${ }^{10}$ from the Eyring plots.

This order of magnitude indicates an assisted pathway with the acyl bridge as trigger. Based on the observed intermediates in the NMR spectra, a mechanistic proposal of the framework isomerization will be discussed.

As mentioned in the preparative section, it was possible to separate metallatetrahedron cluster complexes as pure or nearly pure diastereomers. The CD spectra of such diastereomers were measured in methanol solution at room temperature. The CD data obtained will be taken for correlations, for example, the dependence of CD data on a change of coin metals in a distinct type of diastereomer and those within the symmetry of the metal framework $\left(C_{\mathrm{l}}, C_{\mathrm{s}}\right)$, and the relevance of enantiomeric pure ligands used ${ }^{11}$.

\section{Homogeneous catalysts}

Here the results of hydroformylation reactions in a catalytic process are described. The unmodified triangular clusters $\mathrm{M}_{2} \mathrm{Rh}\left(\mathrm{mPR}_{2}\right)(\mathrm{mCO})_{2}\left(\mathrm{CO}_{8}\right)(\mathrm{M}=\mathrm{Mn}, \mathrm{Re} ; \mathrm{R}=\mathrm{Cy}, \mathrm{Ph})$ showed strong dependence of the chemoselectivity on the type of the $d^{7}$ transition metal used in the course of a catalytic hydroformylation reaction with the substrate 1-hexene. It has therefore been assumed that this dependence was combined with a cooperative effect of these metal atoms in the catalytic process. Whereas the dirhenium catalyst favoured the formation of $n$-heptanal and 2-methylhexanal; the dimanganese catalyst preferred the formation of 1-hexene isomerization products. All catalysts did not generate hydrogenation of the olefins used and aldehydes observed. This is an advantage in view

Table 1. Kinetic data.

\begin{tabular}{lccccc}
\hline $\mathrm{T}[\mathrm{K}]$ & $k_{1} / 10^{-5}{ }_{\mathrm{s}}\left[\mathrm{s}^{-1}\right]$ & $k_{-1} / 10^{-5}\left[\mathrm{~s}^{-1}\right]$ & $K_{\mathrm{c}}$ & $d e \%$ & $r^{2}$ \\
\hline${ }^{31}$ P NMR method & & & & \\
298 & & & & \\
$2.22(13)$ & $5.63(25)$ & 0.394 & 43.5 & 0.993 \\
Polarimetric method & & & & \\
$298 \quad 2.68(10)$ & $6.71(20)$ & 0.399 & 43.0 & 0.997 \\
\hline
\end{tabular}

Table 2. Thermodynamic data of the activation process.

\begin{tabular}{lcc}
\hline & $k_{1}$ & $k_{-1}$ \\
\hline$\Delta H^{\text {o\# }}$ & $84(2)$ & $81(2)$ \\
$\Delta S^{\text {o\# }}$ & $53(5)$ & $55(5)$ \\
$\Delta G^{\text {o\# }}$ & $99(3)$ & $98(3)$ \\
\hline
\end{tabular}


of the industrial mononuclear homogeneous catalysts known. The variation of the organyl residues attached at the phosphido bridge from cyclohexyl to the phenyl groups showed a decrease of the hydroformylation reaction, the isomerization ratio and the total catalytic activity. A common fact of the catalysts is that an exchange of the solvent (THF, $\left.\mathrm{CHCl}_{3}\right)$ changes the activity and the chemoselectivity in the reaction process. The weakly coordinated ligand THF when present as a solvent always gave a lower catalytic activity and selectivity with respect to the hydroformylation reaction with the solvent chloroform without such coordination property. The yield of the substrate isomerization reaction increases with increasing partial pressure of hydrogen. To optimize the yield of the aldehydes, a low hydrogen pressure seems to be a good choice. With regard to the dependence of this catalyst activity and selectivity on the total pressure, dirhenium rhodium catalysts prefer the hydroformylation reaction but dimanganese rhodium catalysts prefer the isomerization reaction with each of the substrates considered. While dirhenium catalysts reveal the advantageous selectivity of the hydroformylation reaction in the presence of a high total pressure or low substrate concentration, the dimanganese catalysts showed the best results under low total pressure or a high concentration of the substrate in the isomerization reaction.

A modification of the clusters with secondary and tertiary phosphorus organyls improved the stability of the catalysts, whereas the catalyst $\operatorname{Re}_{2} \operatorname{RhPPh}_{3}\left(\mathrm{APCy}_{2}\right)(\mathrm{m}$ $\mathrm{CO})_{2}(\mathrm{CO})_{7}$ vs $\operatorname{Re}_{2} \mathrm{Rh}(\mathrm{CO})\left(\mathrm{mPCy}_{2}\right)(\mathrm{mCO})_{2}(\mathrm{CO})_{7}$ gave an increase of the activity by about $20 \%$. Moreover the chemoselectivity and activity of the cluster complexes was generally dependent on the type of catalyst, the reaction conditions and the substrate used. In the case of the use of 1-hexene instead of 1-pentene, for example, a loss of activity with a simultaneous improvement of the hydroformylation activity resulted. As against this, the isomerization property of the catalyst $\mathrm{MnRh}\left(\mathrm{mPCy}_{2}\right)(\mathrm{mH})(\mathrm{CO})_{5} \mathrm{Mn}\left(\mathrm{mPCy}_{2}\right)$ seemed to be relatively unaffected by different reaction conditions, but a substrate like cyclohexene as the cyclic olefin allowed the change from the dominant isomerization reaction to a hydroformylation reaction ${ }^{12}$.

\section{References}

1. Kaez H D, Shriver D F and Adam R D 1990 The chemistry of metal cluster complexes (New York: VCH)

2. Schmid G 1994 Clusters and colloids (New York: VCH)

3. Haupt H-J, Egold H, Siefert R and Flörke U 1998 Z. Anorg. Allg. Chem. 624 1836; Haupt H-J, Petters D and Flörke U 1999 Z. Anorg. Allg. Chem. 6251652

4. Haupt H-J, Wittbecker R and Flörke U 1996 J. Organomet. Chem. 518213

5. Beckers H-G, Flörke U and Haupt H-J 1995 Angew. Chem., Int. Ed. Engl. 1071464

6. Haupt H-J, Schwefer M and Flörke U 1995 Inorg. Chem. 34 292; 1997 Inorg. Chem. 36184

7. Haupt H-J, Schwefer M, Egold H and Flörke U 1995 Inorg. Chem. 345461

8. Haupt H-J, Schwefer M and Flörke U 1995 Z. Anorg. Allg. Chem. 6211098

9. Haupt H-J, Petters D and Flörke U 1999 Inorg. Chem. (submitted for publication)

10. Siefert R $1998 \mathrm{Ph} \mathrm{D}$ thesis, University of Paderborn, Paderborn

11. Haupt H-J, Seewald O, Flörke U, Buss V and Weyhermüller T J $2000 \mathrm{~J}$. Chem. Soc., Dalton Trans. (in press)

12. Wittbecker R and Haupt H-J (unpublished results) 